\title{
||||||||||||||||||||||||||||||||||||||||||||||||||||||||||||||||||.
}

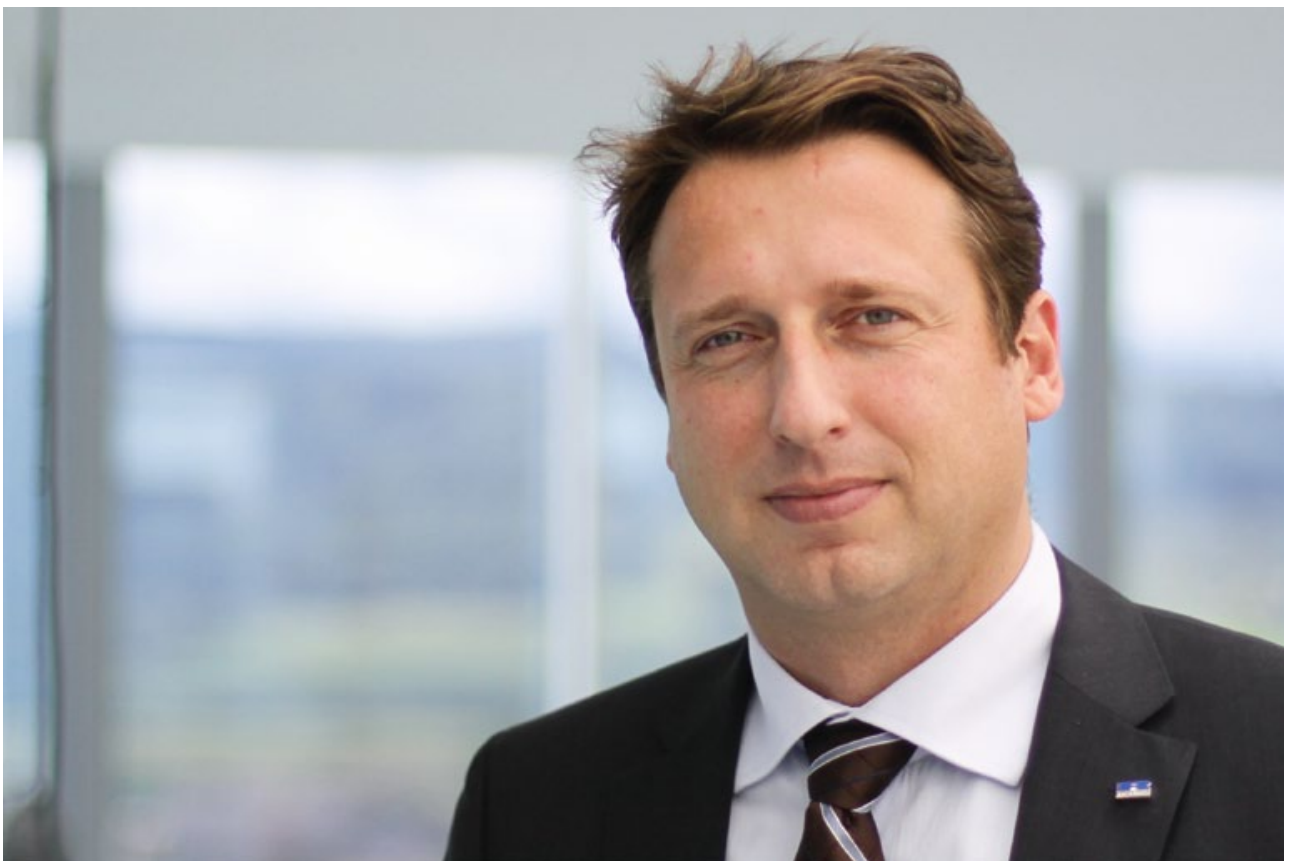

DR.-ING. ROBERT HENTSCHEL

Geschäftsführer der

Ricardo Deutschland GmbH

\section{IM ZENTRUM DES TRIEBSTRANGS}

Hybrid- und Elektrofahrzeuge sind derzeit die auffälligsten Herausforderungen der aktuellen Getriebeentwicklung - Hightech für High-End-Fahrzeuge. Aber ist das alles? Auch die konventionelle Getriebeentwicklung bietet noch großes Potenzial: höhere Gangzahlen, zunehmender Einsatz von Doppelkupplungsgetrieben (DKGs), Weiterentwicklung der Wandlerautomaten und intelligente Automatisierung für preissensible Märkte. Noch nie gab es so viel Innovation in diesem Bereich.

Ricardo ist als globaler Ingenieurdienstleister im Bereich Automotive zu Hause, aber auch in einer Reihe von anderen Marktsektoren wie On- und Off-Highway oder Clean Energy tätig. Unsere Getriebeentwicklung im konventionellen Bereich zielt aktuell auf mehr Gangstufen mit höherer Spreizung bei gleichem oder sogar knapperem Bauraum, Gewichtsreduzierung, Verbesserung der Effizienz, Verbesserung der Wirtschaftlichkeit sowie erfolgreiche Getriebeentwicklungen für die Rennstrecke.

Insbesondere die Technik der Doppelkupplung bietet alternative Architekturen und Konzepte, die ursprüngliche Einführungshindernisse beilegen und neue Marktsegmente erschließen werden.

Das Handschalt-DKG ist eine neue kostenreduzierte Variante, die auf rein mechanischen Systemen ohne die Notwendigkeit elektronischer Steuerung beruht. Dabei bietet es die Vorteile der Doppelkupplung hinsichtlich der Fahrbarkeit in einem deutlich vereinfachten Getriebe - geschaltet wird manuell. Diese Lösung wurde ursprünglich für Nutzfahrzeuge in der
Landwirtschaft erdacht und eröffnet jetzt Anwendungen in einer Reihe von Marktsektoren, angefangen bei Motorrädern über Kleinwagen und, dank der hohen möglichen Drehmomente, auch für Geländefahrzeuge.

Für Hochleistungsfahrzeuge und leichte Lkw bietet sich das HiTorque-DKG an: eine Konfiguration, die Drehmomente bis zu $950 \mathrm{Nm}$ und eine weite Spreizung erlaubt. Die Architektur dieser Familie lässt 8-, 9-, 10- und 12-Gang-Varianten mit leicht anpassbaren Stufungen zu. Eine neue Hochdruckaktuierung bringt geringere Verluste.

Eine neue, alternative Gattung von Getrieben ermöglicht die Funktionalität eines DKG zu den deutlich günstigeren Kosten eines automatisierten Schaltgetriebes (AMT). Bislang konnten sich AMTs aufgrund ihrer Schaltqualität in den meisten Märkten nicht durchsetzen. Die neue Gattung bietet hierfür technische Lösungen. Es gibt sichere Anhaltspunkte dafür, dass die Funktionsweise des DKG zu AMT-Preisen erreichbar ist. Ein solches Getriebe wird Akzeptanz in breiten Schichten des Pkwund Nutzfahrzeugmarkts finden.

Die aktuellen Entwicklungen machen deutlich, dass die zukünftigen Getriebe einen wesentlichen Beitrag zur Reduzierung des $\mathrm{CO}_{2}$-Ausstoßes, Verbesserung der Fahrbarkeit im Allgemeinen, aber auch in Bezug auf autonomes Fahren und Reduzierung der Kosten leisten werden. Blicken wir weiter und denken an den vollständig integrierten Antriebsstrang der Zukunft, so zeigt sich, dass Getriebe wahrhaft im Zentrum dieses Triebstrangs stehen. 